\title{
LIGHT TRAPPING OF THE TURNIP MOTH (AGROTIS SEGETUM DEN. ET SCHIFF.) DEPENDING ON THE GEOMAGNETISM AND MOON PHASES
}

\author{
NOWINSZKY, L.* - PUSKÁS, J. \\ University of West-Hungary Savaria University Centre \\ H-9701 Szombathely Károlyi G. Square 4. \\ *Corresponding author \\ e-mail: lnowinszky@gmail.com \\ (Received $17^{\text {th }}$ April 2011; accepted $26^{\text {th }}$ August 2011)
}

\begin{abstract}
The study deals with the change of light-trap catch of the Turnip Moth (Agrotis segetum Den. et Schiff.), in connection with the horizontal component of geomagnetic field and the moon phases. The numbers of specimens caught by generation relative catch values were calculated. These hourly relative catch data were assigned to the hourly values of horizontal component of geomagnetic field. They were separated by the moonlit and moonless hours of the four quarter of the Moon (New Moon, First Quarter, Full Moon and Last Quarter) were classified. We correlated the hourly catch results pertaining to the hourly values of both the horizontal component and moonlit or moonless hours of four moon quarters. After that we made correlation calculations to demonstrate the assumed connection. Our calculations have shown that in the period of the New Moon when there is no measurable moonlight, the higher values of the horizontal component are accompanied by a falling relative catch. In the other moon phases, i.e. in the First Quarter, Full Moon and the Last Quarter, growing values of the horizontal component are accompanied by an increasing catch in both the moonlit and moonless hours.
\end{abstract}

Keywords: geomagnetic field, lunar month, insects

\section{Introduction}

It has been known for decades that the insects detect the geomagnetic field, and even can use it as a three-dimensional orientation. It is also known for decades that the spatial orientation of the insect is able to use the Moon. We investigated, therefore, that the effectiveness of light-trap catch of insects changes to the combined effect of the horizontal component of the geomagnetic field strength and the moon phases?

A number of laboratory experiments and comprehensive studies are devoted to the physiological bases of perception and the ways of orientation (Wehner and Lobhart, 1970; Kirschvink, 1983; Wehner, 1984 and 1992; Jahn, 1986). Becker (1964) has found that certain species of termites (Isotermes), beetles (Coleoptera), flies (Diptera), orthopteroids (Orthoptera) and membrane-winged insects (Hymenoptera) are guided in their orientation by the natural magnetic field. Mletzko (1969) carried out his experiments with specimens of ground beetles (Broscus cephalotes L., Carabus nemoralis Mull. and Pterostichus vulgaris L.) on a 100 square meter asphalt coated area in the Moscow botanical garden. He placed the insects in the middle of the area and followed their movement with a compass. After some uncertainty, the insects flew in a given direction with an accuracy of $\pm 5^{\circ}$ at daylight and $\pm 60^{\circ}$ at night. The author assumes that orientation is guided by geomagnetism. Iso-Ivari and Koponen (1976) studied the impact of geomagnetism on light trapping in the northernmost part of Finland. In their experiments they used the K index values measured in every three hours, as well as the $\Sigma \mathrm{K}$ and the $\delta \mathrm{H}$ values. A weak but significant correlation was found between the geomagnetic parameters and the 
number of specimens of the various orders of insects caught. Studying the few Willow Ermine (Yponomeuta rorella Hbn.), Pristavko and Karasov (1970) revealed a correlation between the $\mathrm{C}$ and $\Sigma \mathrm{K}$ values and the number of individuals caught. In a later study (Pristavko and Karasov, 1981) they also established that at the time of magnetic storms $\Sigma \mathrm{K}$ has a greater influence on the flying activity of the above species. The influence is also significant in years when $\Sigma \mathrm{K}$ is not higher than 16-26. Equally interesting is the observation that if $\Sigma \mathrm{K} \leq 26$, flying activity intensifies the same day, if $\Sigma \mathrm{K}=27-30$, this happens the following day and if $\Sigma \mathrm{K}=33-41$, intensification follows only on the second or third day. Studying the termite species Heterotermes indicola Wasmann, Becker and Gerisch (1977) found a stronger correlation between this activity and the vertical component of geomagnetism $(\mathrm{Z})$ than with the values of the $\mathrm{K}$ index. Tshernyshev and his colleagues have discussed in a series of studies the results of their laboratory and light trapping experiments with species of different orders of insects to reveal a connection between geomagnetism and certain life phenomena. Tshernyshev (1966) found that the number of light-trapped beetles and bugs rose many times over at the time of geomagnetic storms in Turkmenia. He found a high positive correlation between the horizontal component and the number of trapped insects. In laboratory conditions, Tshernyshev and Danilevsky (1966) could not reveal the influence of an alternating magnetic field on the activity of flies at low temperature $\left(22^{\circ} \mathrm{C}\right)$, but observed a significant rise at $29^{\circ} \mathrm{C}$. Tshernyshev (1968) studied the changes in the biological rhythm of the Trogoderma glabrum Herbst. as a function of the perturbations of the magnetic field. His assessment was based upon the K-index values over 4, i.e. over $40 \gamma$ measures at 6 and 9 p.m. as well as at 3 a.m. It was proved that the biological rhythm of the species observed was influenced by factors that coincided with perturbations of the magnetic field. It was also observed by Tshernyshev (1965) that the number of light-trapped insects significantly rose at the time of magnetic perturbations. Later, however, he reported that while lighttrap catches of some Coloptera and Lepidopera species increased, that of other Lepidoptera and Diptera species fell back during magnetic perturbations (Tshernyshev, 1971 and 1972). Tshernyshev and Afonina (1971) also observed that the activity of certain moths and beetles increased, but in some cases fell back under the influence of a weak and changing magnetic field induced in laboratory conditions. Based on international literature and his own results, Tshernyshev (1989) published a comprehensive study to give a summary of the latest state of knowledge on the relation between geomagnetism and the activity of insects. Tshernyshev and Dantharnarayana (1998) used an infrared actograph to study in laboratory conditions the activity of (Helicoverpa armigera Hbn.), Native Budworm (Helicoverpa punctigera Wallengren) and (Heliothis rubescens Walker). Examining the influence of the geomagnetic $\mathrm{K}$ index also in the context of the four typical lunar quarters (First Quarter, Full Moon, Last Quarter and new Moon), a significant negative correlation was found in the Last Quarter and a positive correlation in the other three. Moths are also disturbed by geomagnetic perturbations. 30 hours after perturbations the influence was still felt.

Examinations over the last decades have also confirmed that some Lepidoptera species, such as Noctua pronuba L. (Baker and Mather, 1982) and Agrotis exclamationis L (Baker, 1987) are guided by both the Moon and geomagnetism in their orientation, and they are even capable of integrating these two sources of information. On cloudy nights, the imagos of Noctua pronuba L. orientated with the help of geomagnetism. In this case, too, their preference lay with the direction they had chosen when getting their orientation by the Moon and the stars. Using hourly data from the material of the Kecskemét 
frationating light-trap, we have examined the light trapping of Turnip Moth (Agrotis segetum Den. et Schiff.), Heart-and-Dart (Agrotis exclamationis L.) and Fall Webworm Moth (Hypantria cunea Drury) in relationship with the horizontal component of the geomagnetic field strength (Kiss et al., 1981; Nowinszky and Tóth, 1983).

According to the authors of recent publications (Srygley and Oliveira, 2001; Gillet and Gardner, 2009; Samia et al., 2010) the orientation/navigation of moths at night may becomes not by the Moon or other celestial light sources, but many other phenomena such as geomagnetism.

The average field strength of the Earth as a magnetic dipole is $33,000 \gamma$. $\left(1 \gamma=10^{-5}\right.$ Gauss $=10^{-9}$ Tesla $=1$ nanotesla (nT)). Geophysical literature uses $\gamma$ as a unit. Geomagnetic field strength can be divided into three components: $\mathrm{H}=$ horizontal, $\mathrm{Z}=$ vertical and $\mathrm{D}=$ declination components. The magnetic and geographic poles of the Earth do not coincide, therefore in addition of geographic; there are also geomagnetic coordinates of latitude and longitude. The latter characterize the geomagnetic conditions of a given geographical location. Geomagnetic parameters greatly differ in any given moment of time at the various points of the surface of the Earth. A distance of approximately 300 kms along the geomagnetic meridian may produce significantly different characteristics. So in Hungary, geomagnetic data registered at a single post of observation will provide sufficient information for the entire territory of the country. These measurements are made at the Geodetical and Geophysical Research Institute of the Hungarian Academy of Sciences at Nagycenk, near Sopron and the Observatory of the Hungarian Loránd Eötvös Geophysical Institute at Tihany.

\section{Material and methods}

The yearbooks of the latter supplied us with the data we needed in our research, namely, those of the horizontal $(\mathrm{H})$ component of the geomagnetic field strength. The yearbooks include values of the horizontal component over $21500 \mathrm{nT}$ over $41800 \mathrm{nT}$. Since the values of the horizontal components of the geomagnetic field strength showed great differences in the years examined, we could work with values over $21250 \mathrm{nT}$ respectively, when processing our light trapping data.

For the purposes of our examination we had at our disposal three years of catch data pertaining to Turnip Moth (Agrotis segetum Den. et Schiff.) from the material of the Kecskemét fractionating light-trap. From the number of specimens caught we calculated relative catch values (RC) by generations. We had stated before in our earlier work (Kiss et al., 1981; Tóth and Nowinszky, 1994) that the impact of geomagnetism on light-trap catches should not be studied without consideration to the prevalent illumination conditions. Therefore we divided our relative catch data to those gained in or in the absence of moonlight and within these two classes established sub-categories according to the Moon phase angle around the four Moon quarters in the following way: In the swarming period of the various species, we calculated the value of the Moon phase angle for the $24^{\text {th }}$ hour (UT) of each night. Then we formed 30 groups of phase angles of the 360 phase angle values of the complete lunar month. The group containing the phase angle values found in the vicinity of a Full Moon $\left(0^{\circ}\right.$, or $\left.360^{\circ}\right) \pm 6^{\circ}$ is marked: 0 . Proceeding from here through the First Quarter in the direction of the new Moon, the groups are marked as: $-1,-2,-3,-4,-5,-6,-7,-8,-9,-10,-11,-12,-13$ and -14 . From the Full Moon through the final quarter in the direction of the new Moon the groups are: 1, 2, $3,4,5,6,7,8,9,10,11,12,13$ and 14. The group of phases containing the new Moon is 
marked: \pm 15 . Each group contains 12-phase angle value. The four typical Moon quarters contain the following phase angle groups: Full Moon $(-2-+2)$, final quarter (3 -9), new Moon (10 - -10) and First Quarter (-9 - -3).

The numbers of specimens caught by generation relative catch values were calculated. These hourly relative catch data were assigned to the hourly values of horizontal component of geomagnetic field. They were separated by the moonlit and moonless hours of the four quarter of the Moon (New Moon, First Quarter, Full Moon and Last Quarter) were classified.

We correlated the hourly catch results pertaining to the hourly values of both the horizontal component and moonlit or moonless hours of four moon quarters. After that we made correlation calculations to demonstrate the assumed connection.

\section{Results and discussion}

The relative catch values of the Turnip Moth (Agrotis segetum Den. et Schiff.) connected to the values of the horizontal component in moonlit and moonless hours of four quarters of the Moon can be seen in Fig. 1, Fig. 2 and Fig. 3.

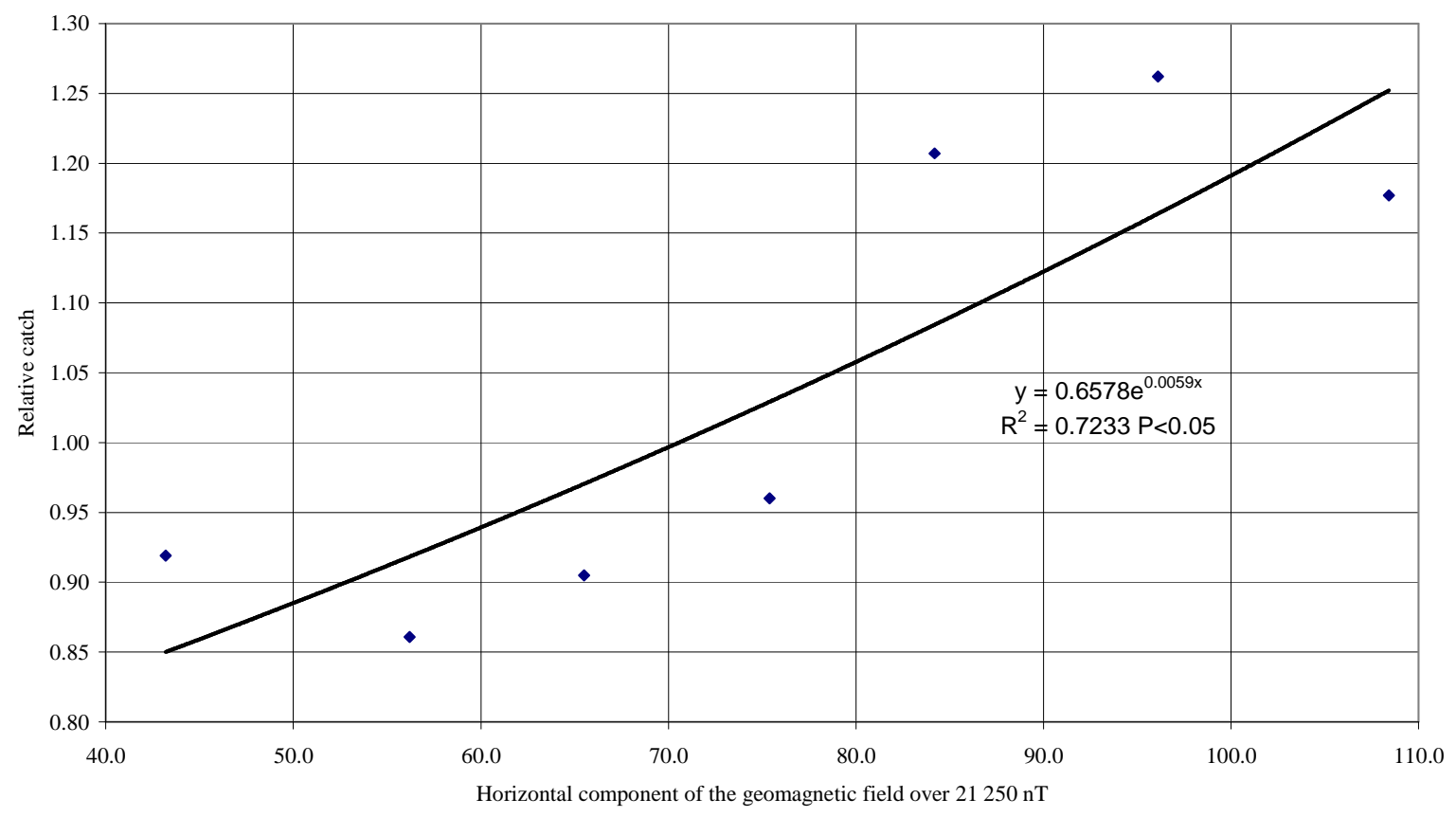

Figure 1. Light-trap catch of the Turnip Moth (Agrotis segetum Den. et Schiff.) in moonlit hours of First- and Last Quarers and Full Moon in connection with the horizontal component of the geomagnetic field over $21250 \mathrm{nT}$

Our calculations with data of the horizontal component supplied by the material of the Kecskemét fractionating light-trap have shown that in the period of the new Moon when there is no measurable moonlight, the higher values of the horizontal component are accompanied by a falling relative catch. In the other Moon phases, i.e. in the First Quarter, Full Moon and the final quarter, growing values of the horizontal component are accompanied by an increasing catch in both the moonlit hour and those without moonlight. So it appears that in the period of lunation in which the presence of the Moon provides insects with orientation information at some time of the night, 
orientation is guided primarily by light stimulus even if the Moon is not over the horizon. Growth of the geomagnetic field strength may generate an intensification of the flying activity of insects, yet, with the role of the light stimulus being of prime importance in orientation, collecting is even more effective. On the other hand, in the vicinity of the new Moon when at no time of the night can insects base their orientation on the Moon, it is presumable that intensifying geomagnetic field strength that increases the security of the orientation of insects will, as against light stimuli, receive an increasingly important role in the process of orientation.

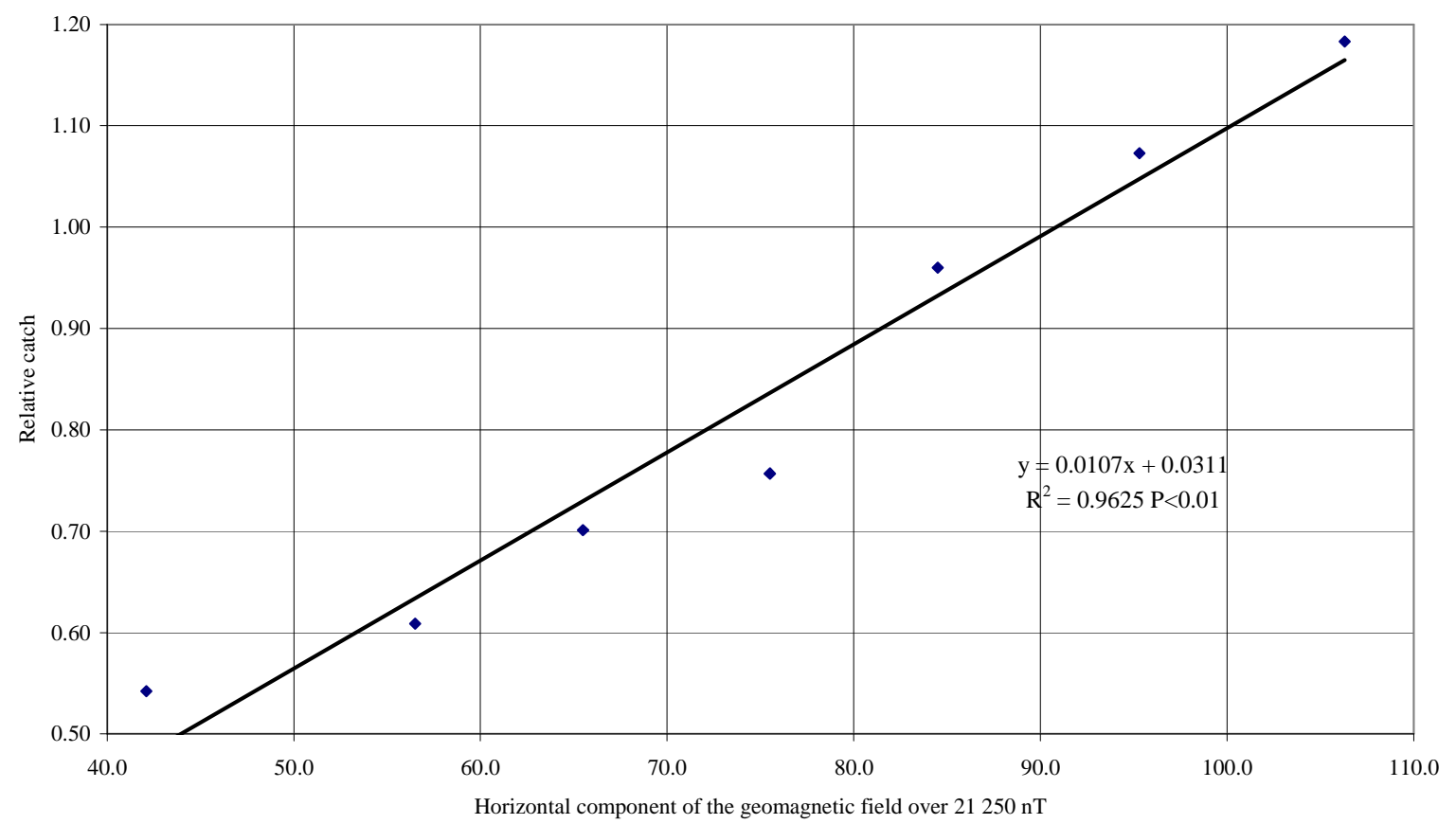

Figure 2. Light-trap catch of the Turnip Moth (Agrotis segetum Den. et Schiff.) in moonless hours of First- and Last Quarers and Full Moon in connection with the horizontal component of the geomagnetic field over $21250 \mathrm{nT}$ 


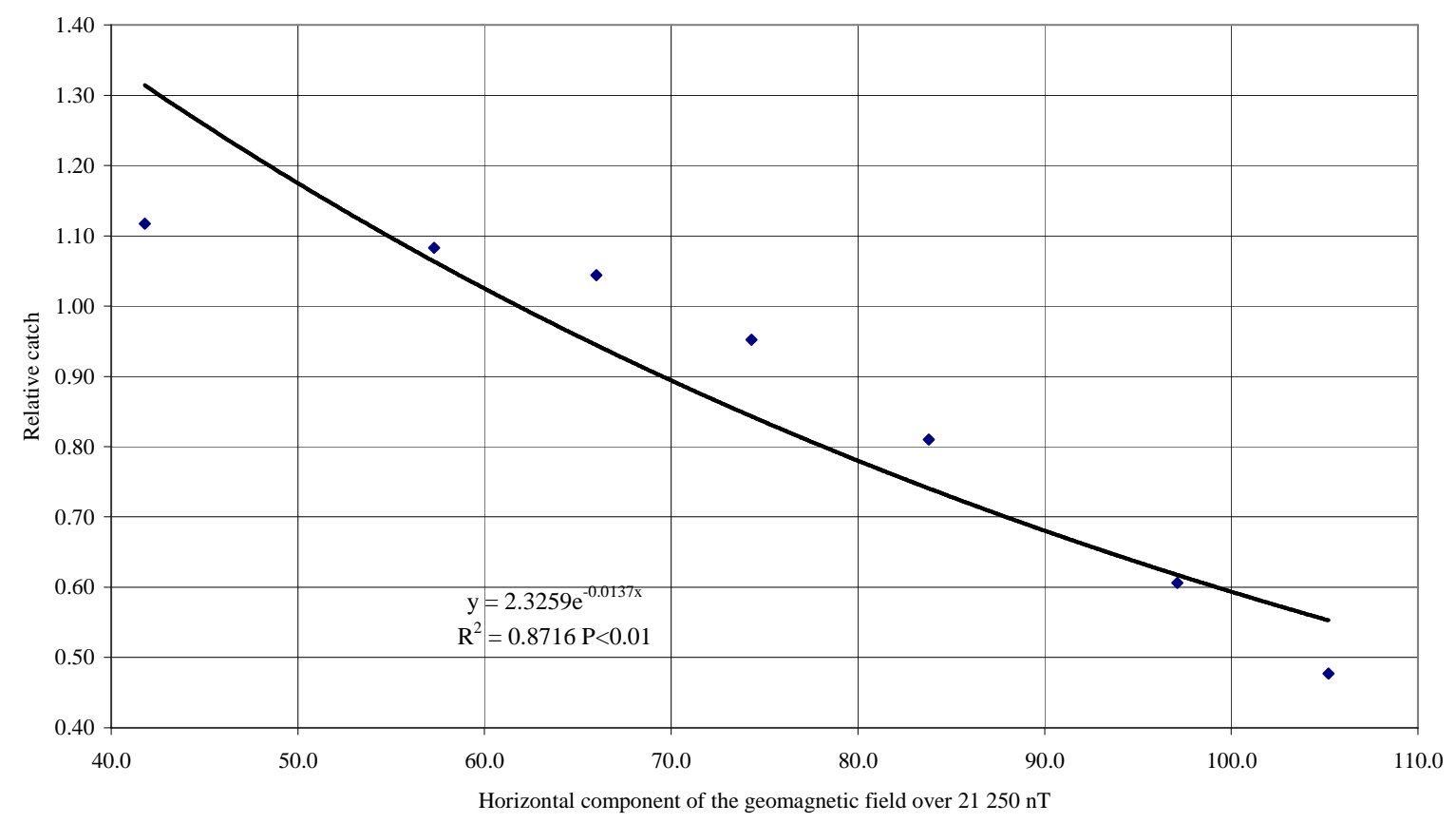

Figure 3. Light-trap catch of the Turnip Moth (Agrotis segetum Den. et Schiff.) in moonless hours of the New Moon in connection with the horizontal component of the geomagnetic field over $21250 n T$

\section{REFERENCES}

[1] Baker, R.R. (1987): Integrated use of moon and magnetic compasses by the heartand-dart moth, Agrotis exclamationis. - Anim. Behav. 35: 94-101.

[2] Baker, R.R., Mather, J.G. (1982): Magnetic compass sense in the large yellow underwing moth, Noctua pronuba L. - Anim. Behav. 30: 543-548.

[3] Becker, G. (1964): Reaktion von Insekten auf Magnetfelder, elektrische Felder und atmos pherics. - Z. ang. Ent. 54(1-2): 75-88.

[4] Becker, G., Gerisch, W. (1973): Zusammenhänge zwischen der Fraßaktivität von Termiten und solaren Einflüssen. - Z. ang. Ent. 73: 365-386.

[5] Gillet, M.P.T., Gardner, A.S. (2009): An unusual observation - attraction of caterpillars to mercury vapour light in the Abu Dhabi (Lepidoptera: Pyralidae) Tribulus 18: 56-59.

[6] Iso-Iivari, L., Koponen, S. (1976): Insect catches by light trap compared with geomagnetic and weather factors in subarctis Lapland. Rep. Kevo Subarctic Res. Stat. 13: 33-35.

[7] Jahn, E. (1986): Physikalische Felder und Insekten. Ein Übersichtsreferat. - Anz. Schädlingskde. Pflanzenschutz, Umweltschutz. 59: 8-14.

[8] Kirschvink, J. L. (1983): Biomagnetic geomagnetism. - Rev. Geophys. 21: 672675.

[9] Kiss, M., Ekk, I., Tóth, Gy., Szabó, S., Nowinszky, L. (1981): Common effect of geomagnetism and change of moon phases on light-trap catches of fall webworm moth (Hyphantria cunea Drury). - Z. ang. Ent. 91: 403-411.

[10] Mletzko, G. G. (1969): Orientation rhythm at Carabidae (in Russian). - Zhurn. Obshch. Biol. 30: 232-233. 
[11] Nowinszky, L. [ed.] (2003): The Handbook of Light Trapping. - Savaria University Press. Szombathely.

[12] Nowinszky, L., Tóth, Gy. (1983): Common effect of geomagnetism and moonlight on the light-trap catches of turnip moth (Scotia segetum Schiff.) (in Hungarian). - Növényvédelem. 19(2): 49-58.

[13] Pristavko, V.P., Karasov, V.Sz. (1970): Application of ultraviolet light-traps to investigation of gnat's population (in Ukrainen). - Visnik Silskogospod Nauki. 10: 69-72.

[14] Pristavko, V.P., Karasov, V.Sz. (1981): The role of variation of geomagnetic field associated with other abiotic factors influencing the fly activity of insects (in Russian). - Minsk. 190-193.

[15] Samia, M.M. Saleh., Layla, A.H. Al-Shareef, Raja, A.A. Al_Zahrany (2010): Effect of geomagnetic field on whitefly Bemisia tabaci (Gennadius) flight to the cardinal and halfway directions and their attraction to different colors in Jeddah of Saudi Arabia - Agric. Biol. J. N. Am. 1(6):1349-1356.

[16] Srygley, R.B., Oliveira, E.G. (2001): Sun compass and wind drift compensation in migrating butterflies. - The Journal of Navigation 54(3): 405-417.

[17] Tshernyshev, V.B. (1965): A symposium held to investigation of the influence of magnetic field on biological objects (in Russian). - Tez. dokl. 80-82.

[18] Tshernyshev, V.B. (1966): Influence of disturbed magnetic field on the activity of insects (in Russian). - Soveschsanie po izucheniyu vliyaniya magnetikh poley na biologicheskie obyekti. Tezisi. 80-83.

[19] Tshernyshev, V.B. (1968): The disturbed magnetic field and the biological rhythm of insect Trogoderma (in Russian). - Zhurn. Obshch. Biol. 26: 719-723.

[20] Tshernyshev, V.B. (1971): The disturbed magnetic field and the moving activity of insects (in Russian). - Vliyanie solnechnoy activnosti na atmosferi i biosferi. Moscow. 215-223.

[21] Tshernyshev, V.B. (1989): Solar activity and the insects (in Russian). - Biofiz. i klin. Sb. nauch. trudov. L.: Nauka (Probl. of Cosmical. Biology. T. 65): 92-99.

[22] Tshernyshev, V.B., Afonina, V.M. (1971): The influence of weak low-frequency magnetic field on several insects (in Russian). - Materiali Vsesoyuz. simpoz. Reakciya biol. system 16-19.

[23] Tshernyshev, V.B., Danilevskiy, M.L. (1966): Influence of variable magnetic field on the activity of Protophormia terrae-novae R.D (in Russian). - Zhurn. Obshch. Biology. 27( 4): 496-498.

[24] Tshernyshev, W.B. (1972): The catches of insects by light trap and solar activity. -Zool. Anz., Leipzig. 188: 452-459.

[25] Tshernyshev, W.B., Danthanarayana, W. (1998): Laboratory study of flight in some noctuids (Lepidoptera: Noctuidae: Heliothinae). 2. Activity from day to day. - Russian Entomol. J. 7(1-2): 96-100.

[26] Wehner, R. (1984): Astronavigation in insects. - Ann. Rev. Entomol. 29: 277298.

[27] Wehner, R. (1992): Hunt for the magnetoreceptor. - Nature, 359: 105-106.

[28] Wehner, R., Lobhart, Th. (1970): Perception of the geomagnetic field in the Drosophila melanogaster. Experientia. 26: 967-968 